Originally published as:

Mühle, M., Löchelt, M., Denner, J.

Optimisation of expression and purification of the feline and primate foamy virus transmembrane envelope proteins using a 96 deep well screen

(2012) Protein Expression and Purification, 81 (1), pp. 96-105.

DOI: 10.1016/j.pep.2011.09.006

This is an author manuscript.

The definitive version is available at: http://www.sciencedirect.com/ 
Protein Expression and Purification

Regular manuscript

\title{
Optimisation of expression and purification of the feline and primate foamy virus transmembrane envelope proteins using a 96 deep well screen
}

\author{
Michael Mühle ${ }^{1}$, Martin Löchelt ${ }^{2}$, Joachim Denner ${ }^{1 *}$ \\ ${ }^{1}$ Robert Koch Institute, Berlin, Nordufer 20, 13553 Germany \\ ${ }^{2}$ German Institute for Cancer Research, Heidelberg, Im Neuenheimer Feld 242, 69120 Germany
}

* Corresponding author.

Robert Koch Institute, Berlin, Nordufer 20, 13553 Germany

Phone: +49 3018754 2800, Fax: +49 30187542801 .

E-mail address: DennerJ@rki.de 


\section{ABSTRACT}

The production of recombinant transmembrane proteins is due to their biochemical properties often troublesome and time consuming. Here the prokaryotic expression and purification of the transmembrane envelope proteins of the feline and primate foamy virus using a screening assay for optimisation of expression in 96 deep well plates is described. Testing simultaneously various bacterial strains, media, temperatures, inducer concentrations and different transformants, conditions for an about twentyfold increased production were quickly determined. These small scale test conditions could be easily scaled up, allowing purification of milligram amounts of recombinant protein. Proteins with a purity of about 95\% were produced using a new purification protocols, they were characterised by gel filtration and circular dichroism and successfully applied in immunological assays screening for foamy virus infection and in immunisation studies. Compared to the previously described protocol (Muehle et al., Virology, 412:333-340, 2011), proteins with similar characteristics but about thirtyfold increased yields were obtained. The screening and production method presented here can also be applied for the production of transmembrane envelope proteins of other retroviruses, including HIV-1.

\section{Key words}

Optimisation of protein expression

High throughput screening

Foamy Viruses

Transmembrane envelope protein

HIV-1 
Abbreviations used: CDNB, 1-chloro-2,4-dinitrobenzene; DDM, n-dodecyl- $\beta$-maltoside; IPTG, $\quad$ isopropyl $\quad \beta$-D-1-thiogalactopyranoside; $\quad$ OPD, $\quad o$-phenylenediamine dihydrochloride; TM protein, transmembrane envelope protein

\section{Introduction}

Technologies for the production and purification of recombinant proteins have been greatly improved in the last years and contributed significantly to the increase of knowledge in the field of proteomics [1]. Although several commercial expression systems are available, establishing an efficient expression and purification protocol for a new protein is still rather cumbersome. Expression in E. coli is a preferred cheap and easy to handle method for small and large scale production [2, 3]. However, when dealing with proteins of mammalian or viral origin, with very large proteins or with proteins containing disulfide bonds, expression levels are often very low $[2,3]$. Expression of transmembrane proteins is even more challenging due to low expression levels, a high tendency to aggregate in inclusion bodies, cellular toxicity and plasmid instability [4]. In such cases, expression has to be optimised thoughtfully to minimize efforts in subsequent large scale purification steps. Usually this is performed by stepwise testing of different vector systems, bacterial hosts, media, as well as the expression conditions itself, e.g., temperature, IPTG concentrations and time point of induction [5]. In this study a single assay is described that allows simultaneous screening for optimal expression parameters and its efficacy was demonstrated on two retroviral transmembrane envelope (TM) proteins that are difficult to express. 
The TM proteins of retroviruses are essential for infection and have been well investigated in the case of the human immunodeficiency virus type 1 (HIV-1) and murine leukaemia virus (MuLV). They consist of a hydrophobic N-terminal fusion peptide, Nand C-terminal alpha helical regions connected through a cysteine loop, and the membrane spanning domain anchoring the protein in the viral membrane. After insertion of the fusion peptide into the cellular membrane, conformational changes and hairpin formation allow infection of the cell [6]. Foamy viruses are retroviruses belonging to the subfamily Spumaretrovirinae $[7,8]$. Due to their large packaging capacity and broad tissue tropism they are of interest as vectors for gene therapy and vaccine applications [911]. The envelope (Env) proteins of the foamy viruses differ in numerous points from those of other retroviruses. They consist of the Env leader protein (Elp) [12], the surface envelope protein and the TM protein [13]. The TM proteins are larger, their central part is characterised by the presence of seven to eight cysteines and numerous potential glycosylation sites $[14,15]$ and electron microscopic pictures demonstrate an unusual trimeric oligomerisation [16]. Recently the TM protein of the feline foamy virus (FFV) was produced and used for serological screening of infections in cats and for immunisation studies [17]. When compared with diagnostic methods based on the detection of antibodies against Gag, detection of antibodies against the TM protein was found to be a reliable diagnostic tool $[17,18]$. In this report, an improved protocol for the expression and purification of this protein as well as for the TM protein of the primate foamy virus (PFV)is described. Since we encountered extreme difficulties producing this protein in the beginning, a small scale expression screen based on 96 deep well plates 
was developed, which proved to be very powerful and allowed optimisation of expression conditions in less than two days.

\section{Material and methods}

\section{Construction of expression plasmids}

The sequence of the ectodomain of the PFV TM protein (ENV-SFVcpz(hu), Uniprot Acc. Nr. P14351, AS 600-961) was amplified by proof-reading PCR using the plasmid pHSRV13 [19] and the primers PFV-ED-Xa 5'aggatctggctctggatctggtatcgagggaagggatattaatgatgaaaactta-3' and PFV-ED rev 5'atactcgagttagtgatggtgatggtgatggtggtgaggetttaagtatcccaagag-3'. The amplicon was subsequently cloned into prokaryotic expression vector pGEX-KG [20] digested by SmaI/XhoI to yield the expression plasmid pGEX-PFV-ED. Similarly, the expression plasmid pGEX-FFV-TMop, containing the codon-optimised sequence of the ectodomain of the TM protein of FFV (ENV-FFV, Uniprot Acc. Nr. $\underline{\text { O56861}}$, amino acids 563-944) was obtained by cloning the corresponding PCR fragment into pGEX-KG using the following primers: FFV-TMop-Xa 5'-aggatctggctctggatctggtatcgagggaagggatctgaacgatcagaaactg-3' and FFV-TMop-rev 5'-atactcgagttagtgatggtgatggtgatggtggtgcgcggtgccaaaaattccacc-3'. All constructs were verified by restriction analysis and sequencing. 


\section{Small scale expression and solubility testing}

Initial expression experiments were performed in E.coli BL21. After transformation, five ml LB-Medium were inoculated with single colonies from LB plates and grown overnight. Cultures were diluted in $20 \mathrm{ml}$ fresh LB media to obtain an $\mathrm{OD}_{600}$ of 0.1 and incubated at $37{ }^{\circ} \mathrm{C}$ for $3 \mathrm{~h}$. One $\mathrm{ml}$ of non-induced cells was taken for SDS PAGE analysis. Expression was induced by addition of $1 \mathrm{mM}$ isopropyl- $\beta-\mathrm{D}-$ thiogalactopyranosid (IPTG), cells were incubated for $3 \mathrm{~h}$ at $37{ }^{\circ} \mathrm{C}$ and $1 \mathrm{ml}$ of induced cells collected. After pelleting (10.000 g, $10 \mathrm{~min})$, remaining cells were lysed in PBS, 0.1 $\mathrm{mg} / \mathrm{ml}$ lysozyme, $50 \mathrm{U} / \mathrm{ml}$ benzonase for $15 \mathrm{~min}$ on ice and subsequently sonicated for $3 \mathrm{x}$ $20 \mathrm{~s}$ using a Branson sonicator equipped with a microtip. Total lysates were collected before separation of soluble and insoluble material by centrifugation $(16.000 \mathrm{~g}, 30 \mathrm{~min})$. The supernatants were saved and pellets were resuspended in equal volumes of PBS with lysozyme. Total lysate, supernatants and pellets were analysed by SDS PAGE.

\section{Expression screening in 96 deep well plates}

To optimise expression conditions, the parental pGEX-KG vector and expression constructs were transformed into E. coli SHuffle T7 Express (NEB), C43 (Lucigen), SCS-1/pSE111 (Stratagene) and Rosetta 2 (Novagen). From each plate, two colonies of different size were selected and grown as day cultures until an $\mathrm{OD}_{600}$ of 0.6 and stored as glycerol stocks. From these stocks overnight cultures were grown in LB medium containing appropriate antibiotics. On the next day, each well of a 96 deep well plate containing one millilitre of either LB (10 g tryptone, $5 \mathrm{~g}$ yeast extract, $170 \mathrm{mM} \mathrm{NaCl}, \mathrm{pH}$ 7.5), 2 YT (16 g tryptone, $10 \mathrm{~g}$ yeast extract, $100 \mathrm{mM} \mathrm{NaCl}, \mathrm{pH} 7.4)$ or TB medium (12 g 


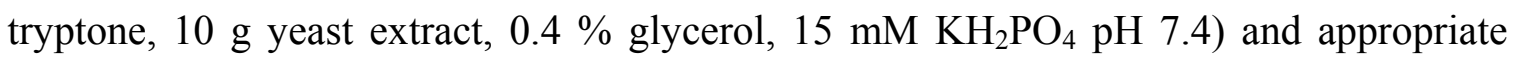
antibiotics was inoculated with $100 \mu 1$ of the stationary overnight culture adjusted to an $\mathrm{OD}_{600}$ of 2.0 and grown for three hours at $37^{\circ} \mathrm{C}$. For induction of protein expression, cultures were adjusted to 0.1 and $1 \mathrm{mM}$ IPTG in parallel to non-induced controls. Empty control vectors were induced with the highest IPTG concentration only. After additional three hours incubation at the indicated temperatures, cells were pelleted by centrifugation for $15 \mathrm{~min}$ at $3700 \mathrm{rpm}$ in an Eppendorf plate centrifuge, lysed by three successive freeze/thaw cycles in liquid nitrogen and subsequently resuspended in $100 \mu 1$ lysis buffer (PBS, $0.1 \mathrm{mg} / \mathrm{ml}$ lysozyme, $50 \mathrm{U} / \mathrm{ml}$ benzonase). For expression analysis $10 \mu 1$ of the total cell lysate were boiled in SDS sample buffer and analysed by SDS-PAGE in a HTPAGE System (CBS Scientific) and Coomassie blue staining.

\section{Large scale production}

For production of milligram quantities of the fusion proteins, optimised conditions from the previous small scale screen were scaled up accordingly. pGEX-FFV-TMop and pGEX-PFV-ED constructs were grown in the BL21 Rosetta 2 host and 1 litre TBMedium per 5 litre baffled flask at $37{ }^{\circ} \mathrm{C}$ until an $\mathrm{OD}_{600}$ of 0.8 , followed by induction with $1 \mathrm{mM}$ IPTG. After three hours of induction, cells were pelleted by centrifugation and stored at $-20^{\circ} \mathrm{C}$ until purification.

\section{Large-scale cell lysis and protein purification}

Cell pellets were resuspended in lysis buffer $2(20 \mathrm{ml} / \mathrm{g}$ cell pellet, PBS, $1 \mathrm{mg} / \mathrm{ml}$ lysozyme, Complete protease inhibitor) and incubated for 15 minutes on ice. The 
suspension was sonicated three times for $20 \mathrm{~s}$ and cell debris was removed by low speed centrifugation (480 g, $10 \mathrm{~min})$. Supernatants were subjected to another centrifugation step at $25.000 \mathrm{~g}\left(1\right.$ hour, $\left.4{ }^{\circ} \mathrm{C}\right)$ and pellets were extracted with lysis buffer 2 containing $1 \%$ sarkosyl (N-lauroylsarcosine, Sigma Aldrich, Germany) for one hour at $4{ }^{\circ} \mathrm{C}$ under shaking. Solubilised proteins were separated from remaining insoluble material by centrifugation $(10.000 \mathrm{~g}, 10 \mathrm{~min})$ and diluted 1:10 with wash buffer (PBS, 0.1\% sarkosyl, $20 \mathrm{mM}$ imidazol, $\mathrm{pH}$ 7.5) before loading on HisTrapFF crude NiNTA affinity columns installed in an Äkta-Explorer 10s FPLC system (all GE Healthcare, Germany). The columns were washed intensively with washing buffer until an $\mathrm{OD}_{280}$ below 0.01 absorption units and eluted using a 20 column volumes gradient with elution buffer (PBS, $0.1 \%$ sarkosyl, $500 \mathrm{mM}$ imidazol, $\mathrm{pH}$ 7.5). Protein concentration was estimated by absorption at $280 \mathrm{~nm}$ using calculated molar extinction coefficients of $\varepsilon=1.561,1.488$, 1.550 and $1.399 \mathrm{~L} / \mathrm{mol}^{*} \mathrm{~cm}$ for the glutathion-S-transferase (GST) fusion proteins of the TM proteins of FFV and PFV or the cleaved TM proteins of FFV and PFV, respectively.

\section{Glutathion S-transferase (GST) assay}

The GST activity of bacterial lysates or purified GST fusion proteins was analysed using CDNB (1-chloro-2,4-dinitrobenzene, Sigma-Aldrich). The colorimetric GS-DNB conjugate was detected at $340 \mathrm{~nm}$ using a Tecan Reader and 96 well plates (Nunc). Samples were measured in one minute intervals for 10 minutes. after addition of $100 \mu 1$ substrate solution, which was freshly prepared using $94 \mu$ l CDNB dilution buffer (100 mM sodium phosphate buffer, $1 \mathrm{mM}$ EDTA, $\mathrm{pH}$ 6.5), $3 \mu \mathrm{CDNB}$ substrate solution (30 $\mathrm{mM}$ CDNB substrate in 95\% ethanol) and $3 \mu \mathrm{l}$ CDNB glutathione solution C (75 mM 
reduced glutathione in CDNB dilution buffer) per well. All measurements were performed in triplicates.

\section{Removal of GST by protease treatment}

To remove the GST moiety, purified proteins with concentrations of at least $0.5 \mu \mathrm{g} / \mu \mathrm{l}$ were cleaved with thrombin protease (Sigma-Aldrich) at a ratio of 12.5 units protease per milligram protein for three hours at $37{ }^{\circ} \mathrm{C}$ under gently shaking. To remove thrombin protease and released GST, the digestion mixture was diluted 1:10 with wash buffer and subjected to an additional affinity purification step using the C-terminal His-tag as described above.

\section{Gelfiltration}

The GST fusion proteins of the TM protein of FFV and PFV, purified by NI-NTA affinity purification, were subjected to gel filtration in a Superdex 200 10/300 GL column (GE Healthcare, Germany) equilibrated with gel filtration buffer (PBS, 0.1\% sarkosyl, $\mathrm{pH} 7.5$ ) and eluted isocratically with a flow rate of $0.4 \mathrm{ml} / \mathrm{min}$ for 1.2 column volumes. Main peaks of the obtained chromatogram were analysed by SDS PAGE and Coomassie blue staining. Protease treated proteins were analysed on a gel filtration buffer equilibrated Superdex 75 10/300 GL column (GE Healthcare) at flow rates of $0.4 \mathrm{ml} / \mathrm{min}$. For CD measurements buffer exchange was performed by loading proteins onto Superdex 200 10/300 columns equilibrated with $10 \mathrm{mM} \mathrm{NaH}_{2} \mathrm{PO}_{4}, 0.02 \%$ (w/v) n-dodecyl-beta-Dmaltoside, $\mathrm{pH} 7.5$ and if necessary concentrated with Vivaspin 6 columns with a MWCO of $5 \mathrm{kDa}$, Sartorius, Germany) 


\section{CD spectroscopy}

Purified proteins were measured in a Jasco 720 spectropolarimeter in $0.01 \mathrm{~cm}$ quartz cuvettes with $0.1 \mathrm{~nm}$ dot pitch and $50 \mathrm{~nm} / \mathrm{min}$ scanning speed in the range of 260-190 nm. Ellipticity $\theta$ was calculated with obtained $\mathrm{CD}$ data in millidegrees, mean residue weights of $114.4,111.3,113.5$ and $111.9 \mathrm{~g} / \mathrm{mol}$ and protein concentrations of $0.21,0.28$, 0.20 and $0.27 \mathrm{mg} / \mathrm{ml}$ for the GST-TM and TM proteins of FFV, and the GST-TM and TM proteins of PFV, respectively. Spectra are means of ten individual measurements performed at room temperature subtracted by the mean spectrum obtained with buffer. For estimation of secondary structures, CD data were analysed with SELCON3, CDSSTR and CONTINLL programs which are part of the CDpro software package [21, 22] using the SMP56 protein reference set which includes spectra of 40 soluble and 13 membrane proteins and which is optimised for interpretation of spectra in the range of 190-240 nm [23, 24]. Amino acid based secondary structure predictions were obtained with the PROFsec algorithm included in the PredictProtein package [25].

\section{ELISA}

Recombinant antigens were purified either by the urea/on-column refolding protocol or by the sarkosyl extraction method, diluted in distilled water and coated overnight at $37^{\circ} \mathrm{C}$ to 96 well plates (200 ng per well). After washing once with PBS-T (phosphate buffered saline, $0.05 \%$ Tween 20 ) and blocking with blocking buffer (1\% non-fat dry milk in PBS-T), triplicates of sera diluted 1:100 in blocking buffer were added to the wells and incubated for one hour at $37^{\circ} \mathrm{C}$. After washing three times with PBS-T, HRP (horseradish peroxidase)-conjugated anti-cat IgG antibody (Bethyl Laboratories, dilution 1:3000) was added for one hour at $37^{\circ} \mathrm{C}$ and plates then washed 
seven times using PBS-T. Detection was performed using OPD (o-phenylenediamine dihydrochloride) substrate dissolved in PBS containing hydrogen peroxide and the absorbance was measured at $492 \mathrm{~nm}$ and $620 \mathrm{~nm}$ after 10 minutes of incubation. As controls a TM protein specific antiserum (goat serum 348, [17]) and the secondary antibody were used. Cut offs were calculated as the mean absorbance of 14 included negative sera plus 2.743 times the mean standard deviation corresponding to a statistical confidence level of 99\% [26]. Absolute cut off values were $211 \mathrm{mAU}$ and $207 \mathrm{mAU}$ for the on-column refolded and sarkosyl extracted TM protein of FFV, respectively.

\section{Results}

\section{Cloning strategy and expression plasmids}

In first attempts to express the TM proteins of FFV and PFV, plasmid constructs were generated by cloning the TM ectodomain lacking the fusion peptide but containing either an N-terminal GST or His-tag. Using GST tagged proteins, only very low (PFV) or absence (FFV) of expression of the TM protein was observed (data not shown). Both recombinant proteins were highly insoluble that prevented purification using glutathione sepharose. Furthermore, numerous breakdown products were found. When the proteins were expressed with an N-terminal His-Tag, expression was very low and detectable only by Western blot analysis, indicating that the GST fusion partner contributed to an increased expression (data not shown). To employ the advantages of both tags, constructs with an N-terminal GST-tag and a C-terminal His-tag were generated (Fig. 1). In case of

the TM protein of FFV, a codon-optimised sequence was used to enhance expression in 
E. coli. This construct showed a fivefold increased expression compared to the noncodon-optimised sequence (not shown). To allow removal of the GST moiety either the thrombin cleavage site encoded by the vector could be used or an additional factor Xa cleavage site was introduced by PCR (Fig. 1A). Whereas thrombin cleavage resulted in recombinant proteins containing twelve vector-derived amino acids, factor Xa digestion allows removal of all unrelated amino acids (Fig. 1A). A schematic presentation of the TM proteins of FFV and PFV and the produced recombinant proteins is given in Fig. 1B.

\section{Small scale expression and expression optimisation}

Similar to the findings of the first expression constructs, both double tagged proteins were also poorly expressed and insoluble in E. coli BL21 under standard expression conditions (Fig. S1). To improve expression levels and solubility, different bacterial host, media, temperature, and inducer concentrations were tested. The 96 deep-well format offered best opportunities to analyse all conditions in parallel (Fig. 2). In addition, the plate layout allowed direct transfer of lysates to SDS PAGE using multichannel pipettes. Prior to screening, plasmid constructs were transformed into four specialised E. coli strains with various genetic backgrounds, chosen to fit the particular properties of both proteins: Shuffle T7 Express cells have been designed for proteins containing cysteines residues allowing formation of disulfide bonds in the cytosol of E.coli by overexpression of the cytoplasmic disulfide isomerase DsbC [27, 28], C43 cells contain an uncharacterised mutation compensating for expression of toxic and particular membrane proteins $[4,29]$, SCS-1/pSE111 cells are K12 derivatives containing the pSE111 plasmid supplying arginine t-RNAs for improved expression of eukaryotic proteins. Similarly, the 
Rosetta 2 strain supplies tRNAs of seven codons rarely produced in E.coli but has the genetic background of the BL21 strain [30]. Since protein expression may vary significantly between individual transformants [31], two clones were selected for analysis together with the parental GST expressing vector as control. In addition, the influence of the media, either standard LB medium, enriched 2YT medium or terrific broth (TB) was tested. Solubility of recombinant proteins often increases when expression levels were reduced, either due to a slower error rate during translation or prolonged time for refolding processes resulting in a lower probability of aggregate formation [32]. Thus, expression at two IPTG concentrations and a non-induced control at temperatures of 16 ${ }^{\circ} \mathrm{C}$ and $37{ }^{\circ} \mathrm{C}$ were tested. Since protein expression was nearly identical at both temperatures (not shown), only results obtained at $37{ }^{\circ} \mathrm{C}$ are presented here (Fig. 3). In case of the PFV-TM protein, good expression levels were achieved in three of the four bacterial hosts tested (Shuffle T7, SCS-1, Rosetta 2) but only weak expression was obtained in the C43 host (Fig. 4A). Minor differences in the expression levels were found when three different media and individual transformants were compared (Fig. 3A, lane LB, 2YT, TB and lane TM1 and TM2, respectively). However, as expected, expression increased at higher IPTG concentrations ( 0.1 to $1 \mathrm{mM}$, Fig. 3A). In the case of the TM protein of $\mathrm{FFV}$, more striking differences were found when the various conditions were compared. Three of the four bacterial strains (Shuffle T7, C43, Rosetta 2) showed high expression levels, whereas no recombinant protein was produced in the SCS-1/pSE111 K12 derivative (Fig. 3B). Importantly, in the three expression strains tested, only bacteria grown in TB medium produced satisfactory amounts of protein, suggesting a highly advantageous role of glycerol as an additional carbon source. Production yields were 
doubled by increasing IPTG concentrations from 0.1 to $1 \mathrm{mM}$ (Fig. 3B). No differences were observed when two different clones were compared (Fig. 3B, TM1 and TM2). Even under mild expression conditions $\left(16^{\circ} \mathrm{C}\right.$ and $0.1 \mathrm{mM}$ IPTG) only small amounts (PFV) or no TM protein (FFV) were found in the supernatant (Fig. S2), indicating that despite different levels of expression, none of the bacterial strains or growth conditions had a beneficial effect on protein solubility.

\section{Detergent screening}

To increase protein solubility during the purification process, various detergents were analysed for their ability to solubilise both proteins from the insoluble fraction. Whereas strong anionic detergents were as expected very efficient, none of the tested non-ionic detergents except Brij35 (10\%) allowed solubilisation of the proteins (Fig. S3). However, binding to glutathione sepharose as well as the enzymatic activity of GST using CDNB as substrate were disturbed under these conditions (data not shown). Addition of the same detergents including Brij35 during cell lysis did also not increase solubility (not shown). Adopting a protocol described for the purification of insoluble actin [33], sarkosyl was added during bacterial lysis to prevent precipitation of the TM proteins. Although this approach brought about 50\% enzymatically active GST-TM proteins into solution at a concentration of $0.3 \%(\mathrm{w} / \mathrm{v})$ sarkosyl (the critical micelle concentration is $0.4 \% \mathrm{w} / \mathrm{v}$ ), GST activity was not longer detected when affinity purified proteins were measured in the same assay (Fig. S4 and not shown). 


\section{Large scale production and purification}

Since the highest expression levels of both proteins with the lowest amounts of background proteins were observed when the Rosetta 2 strain and TB media were used, these conditions were selected for large scale production of both proteins. Although altered aeration conditions in cultures without external oxygen supply, loss of expression plasmids or reduction of the $\mathrm{pH}$ due to cell metabolites have been described to reduce protein yields when scaling-up small scale experiments [3,34], such negative effects were not observed when both TM proteins were produced using Rosetta 2 cells and the optimised conditions. Since attempts to purify both proteins under non-denaturing conditions failed, a denaturing purification strategy was applied. Both GST-fusion proteins were extracted from the insoluble fraction by incubation with $1 \%$ sarkosyl followed by a subsequent refolding step by dilution of the lysate before affinity purification (see Material and methods). Using this purification protocol the protein yields of the TM protein of FFV was drastically improved from about $0.5-0.8 \mathrm{mg} / \mathrm{l}$ originally obtained with the previously described on-column refolding protocol [17] up to 14-16 mg/l (Table 1). The protein yields obtained for the TM protein of PFV were in the same range (15-18 mg/l, Table 1). The sarkosyl purification protocol was less efficient concerning purity when compared to the urea/on-column refolding protocol $(95 \%$ compared to $90 \%$ purity, Table 1). This lower purity is attributed to two proteins migrating at 42 and $34 \mathrm{kDa}$ which were commonly detected by SDS-PAGE (Fig. 4A and B, lane IN). Since these proteins were also detected by anti-His antibodies (not shown), they probably represent breakdown products of the TM proteins lacking the GST or GST and linker residues. The addition of protease inhibitors during lysis did not prevent their 
occurrence; therefore, they might be a result of instability at the flexible linker amino acids located between GST and the TM proteins.

\section{Analysis of protein aggregation}

To analyse the aggregation state of the purified proteins, protein samples from affinity purification steps were subjected to gel filtration (Fig 4). For the TM protein of FFV the chromatogram showed a prominent peak at $10.05 \mathrm{ml}$ and two smaller peaks eluting at $11.95 \mathrm{ml}$ and $13.8 \mathrm{ml}$ (Fig. 4A). SDS PAGE analysis of the elution fractions showed the GST TM protein of FFV with the expected molecular weight of $68 \mathrm{kDa}$ and small amounts of higher molecular weight aggregates migrating at $130 \mathrm{kDa}, 200 \mathrm{kDa}$ and some close to the void volume (Fig. 4 inset). In the residual fractions, breakdown proteins with the molecular weights of 42 and $34 \mathrm{kDa}$ were found (Fig. 4A, lanes 5-7). For the TM protein of PFV the elution patterns were similar (Fig. 4B), however, this protein showed a higher tendency to aggregate and to form multimeric species at 130 and $200 \mathrm{kDa}$ compared to the FFV GST TM protein (compare lanes 2 of Fig 4 A and B). These results indicate that most of the sarkosyl extracted GST TM proteins were in a non-aggregated, monomeric form.

\section{Removal of the GST fusion by protease treatment}

To obtain proteins lacking the GST residue, proteins purified by gel filtration (Fig. 5A and B, lane E) were treated with either factor Xa or thrombin protease. Whereas removal of GST by factor Xa digestion resulted in incomplete cleavage at high enzyme concentrations and prolonged incubation times (data not shown), cleavage with thrombin 
at 12.5 units per milligram protein (ratio 1:80) achieved complete digestion within three hours. After an additional affinity purification step, pure TM proteins of FFV and PFV with minor degradation products were obtained (Fig. 5A and B, lane $\mathrm{E}_{\mathrm{T}}$ ). Gel filtration of these proteins confirmed that they were predominantly non-aggregated (Fig. 6).

\section{Secondary structure analysis using CD spectroscopy}

To assess the secondary structures, proteins were analysed by CD spectroscopy and the results were compared to secondary structure predictions obtained by bioinformatic analysis. Sarkosyl is strongly absorbing at wavelengths below $220 \mathrm{~nm}$ and thus had to be replaced by a non-interfering detergent for this purpose. By testing CD spectroscopy compatible detergents, $\mathrm{n}$-dodecyl- $\beta$-maltoside (DDM) was found not to allow aggregation (data not shown). The buffer was exchanged by gel filtration and spectra were measured at wavelengths of 260-195 nm (Fig. 7). Typical pattern of alpha helical secondary structures with the characteristic plateaus at 222 and $208 \mathrm{~nm}$ and increased ellipticity at $195 \mathrm{~nm}$ [35] were found. When proteins with and without the GST fusion part were measured, only minor differences were found (Fig. 7A and B, solid and dashed lines). However, the TM proteins of FFV and PFV varied slightly, in particular at 215-208 nm, were negative ellipticity values were much more pronounced for the TM protein of FFV. By extracting the structural data from the measured spectra by fitting algorithms included in the CDpro software package and the SMP56 reference spectra, CONTINLL provided the closest approximation to the measured spectra. When these results were compared to amino acid based predictions (Table 2), a good correlation was found. 
Screening for FFV infection using proteins from both purification protocols

To compare the ability to detect antibodies in sera of infected cats using the TM protein of FFV purified by the sarkosyl extraction method with that obtained by on-column refolding as used recently,[17], a comparative ELISA was performed. 30 sera with known FFV serological status (16 positive, 14 negative as determined previously by ELISA using Gag, Bet and TM proteins and immunoblots using infected CRFK cells [17, 18]) were selected for this screening. Both ELISA detected 16 of the 16 FFV positive sera (Fig 8)., indicating that both proteins were equally suitable for serological screening.

\section{Discussion}

In the present study, an improved protocol for the expression and purification of the large TM proteins of two retroviruses of the Spumaretrovirinae sub-family, PFV and FFV, is described. Using a screening method based on 96 deep well plates for optimisation, optimal expression conditions were rapidly determined and transferred to large scale. By optimisation of expression and the use of a detergent based purification protocol, yields of both TM proteins were increased to 14 to $18 \mathrm{mg}$ protein per litre with purity about 95\%. Gel filtration and circular dichroism experiments showed that the obtained proteins were predominantly non-aggregated and possessed defined secondary structures. In case of the TM protein of the FFV the protein purified by this means was found to be similarly suitable to detect FFV infection as the FFV TM antigen described previously [17]. In case of the PFV TM protein, immunisation experiments have been performed and an ELISA for the detection of PFV infection is currently under development. 
To obtain sufficient amounts of the TM proteins of PFV and FFV, several expression parameters were investigated. Although both TM proteins are closely related, remarkable differences in production were found. Among all parameters tested, the E. coli producer cell and the growth medium had the strongest influence on the expression levels. In terms of the bacterial host used, expression seemed to follow an 'all or nothing' principle: whereas the differences in expression levels in producing bacteria were neglectable, other bacteria did not produce the protein even when the expression parameters were varied (Fig. 3). For both TM proteins, the bacterial strains Shuffle T7 and Rosetta 2 were most suitable, possibly due to improved disulfide binding (Shuffle T7) and supplementation of seven t-RNAs (Rosetta 2). However, in case of the TM protein of FFV this result is somewhat unexpected since the sequence was codonoptimised. Interestingly, only one medium, Terrific broth (TB) medium, which contains glycerol as additional carbon source, supported the production of the TM protein of FFV (Fig. 3).

In contrast to expression experiments in E. coli at high cell density [31], there were no significant differences between individual transformants selected for screening. As a consequence, future screening could be modified by including additional vectors carrying other fusion partners (e.g. maltose binding protein (MBP), NusA, thioredoxin) instead of analysis of different clones. A strong influence of the fusion partner on protein expression and solubility has been described repeatedly [36-38]. In order to facilitate testing for solubility of the produced protein, an additional centrifugation step using filter plates or an ultracentrifugation step using 96 well plates may also be included to remove insoluble material [38-40]. 
Selection of different bacterial host cells and changing growth temperature or IPTG concentrations did not have any effect on protein solubility. This surely can be attributed to the nature of the proteins expressed here, two retroviral TM proteins. Although only the ectodomains of the TM proteins lacking the hydrophobic fusion peptide and the membrane spanning domain were expressed, the proteins were insoluble. This may be explained by the interaction of the two helical regions which are naturally interacting during infection resulting in a six-helix-bundle formation. However, the extreme insolubility of the TM proteins of the FV is in contrast to solubility of the TM proteins of different gammaretroviruses also expressed in E.coli. As was shown for the porcine endogenous retrovirus (PERV) [41], the feline leukaemia virus (FeLV) [42] and the Koala virus (KoRV) [43] these proteins were partly soluble and were successfully used for induction of neutralising antibodies and serological testing. p15E of PERV is now part of a newly developed assay to screen animals and human recipients for transmission of PERV during experimental and clinical xenotransplantation [44, 45]. The TM proteins of the gammaretroviruses are small $(15 \mathrm{kDa})$ and non-glycosylated, whereas the TM proteins of the foamy viruses are much larger (gp48), they contain seven to eight cysteines and are highly glycosylated [15]. This resembles the situation described for the lentiviral TM proteins of HIV-1 (gp41) and HIV-2 (gp36), which are also not soluble in aqueous solutions (our own unpublished observations and [46]).

Both TM proteins could be partially resolubilised at detergent concentrations known to preserve biological function of proteins [47]. Although the GST activity could be measured under these conditions in cell lysates, the purified proteins did loose their 
activity after affinity purification. This is possibly due to the high protein concentration during elution and may be prevented by different buffer conditions.

The conformation of the TM proteins is important for their application in diagnostic assays as well as in immunisation studies. Proteins obtained with the method described here were sufficient for screening for FFV infection in cats using ELISA and Western blot analyses (Fig. 8). Although the purification protocol used here differs from the previous one using denaturing conditions followed by an on-column refolding step [17] no differences in the ELISA performance were observed (Fig. 8). Together with the results from CD spectroscopy (Fig. 7) and bioinformatic predictions (Table 2), this suggests that essential structural elements necessary for antibody recognition in sera of infected cats were restored by the dilution-refolding protocol applied here.

Despite this, immunisation studies using purified TM proteins of both foamy viruses as a potential vaccine antigen were not successful and although high titres of binding antibodies were induced, they were not able to neutralise FFV or PFV ([17] and unpublished). Whereas induction of neutralising antibodies immunising with the ectodomain of the TM protein of gammaretroviruses was easily achieved [41-43] all attempts to obtain such antibodies for HIV-1 and HIV-2 using similar proteins also failed $[46,48]$. As already pointed out, the TM proteins of the gammaretroviruses are rather small and not glycosylated, whereas the TM proteins of HIV-1, HIV-2, FFV and PFV are heavily glycosylated and stabilised by cysteine bridges. The influence of different parameters on the conformation of the TM proteins of the lenti- and spumaviruses and their ability to induce neutralising antibodies is largely unknown, and it is unclear whether glycosylation may contribute to generate a suitable conformation for the 
induction of neutralising antibodies. Comparative structural, functional, and immunological studies using small (gammaretroviruses) and large (lenti- and foamy viruses) TM proteins of distantly related retroviruses may allow defining common and unique requirements for protein production and purification and may thus offer the chance for designing novel candidate vaccines against retroviruses including HIV-1.

\section{Acknowledgments}

We thank J. Kreutzberger for constructive advices, A. Sach for technical assistance and N. Jahnke, Research Institute for Molecular Pharmacology, Berlin, for help with CD measurements. The project is supported by the Volkswagenstiftung.

\section{References}

[1] P. Braun, J. LaBaer, High throughput protein production for functional proteomics. Trends. Biotechnol. 21 (2003) 383-388.

[2] S. Graslund, P. Nordlund, J. Weigelt, B.M. Hallberg, J. Bray, O. Gileadi, S. Knapp, U. Oppermann, C. Arrowsmith, R. Hui, J. Ming, S. dhe-Paganon, H.W. Park, A. Savchenko, A. Yee, A. Edwards, R. Vincentelli, C. Cambillau, R. Kim, S.H. Kim, Z. Rao, Y. Shi, T.C. Terwilliger, C.Y. Kim, L.W. Hung, G.S. Waldo, Y. Peleg, S. Albeck, T. Unger, O. Dym, J. Prilusky, J.L. Sussman, R.C. Stevens, S.A. Lesley, I.A. Wilson, A. Joachimiak, F. Collart, I. Dementieva, M.I. Donnelly, W.H. Eschenfeldt, Y. Kim, L. Stols, R. Wu, M. Zhou, S.K. Burley, J.S. Emtage, J.M. Sauder, D. Thompson, K. Bain, J. Luz, T. Gheyi, F. Zhang, S. Atwell, S.C. Almo, J.B. Bonanno, A. Fiser, S. Swaminathan, F.W. Studier, M.R. Chance, A. Sali, T.B. Acton, R. Xiao, L. Zhao, L.C. Ma, J.F. Hunt, L. Tong, K. Cunningham, M. Inouye, S. Anderson, H. Janjua, R. Shastry, C.K. Ho, D. Wang, H. Wang, M. Jiang, G.T. Montelione, D.I. Stuart, R.J. Owens, S. Daenke, A. Schutz, U. Heinemann, S. Yokoyama, K. Bussow, K.C. Gunsalus, Protein production and purification. Nat. Methods 5 (2008) 135-146.

[3] S. Jana, J.K. Deb, Strategies for efficient production of heterologous proteins in Escherichia coli. Appl. Microbiol. Biotechnol. 67 (2005) 289-298.

[4] B. Miroux, J.E. Walker, Over-production of proteins in Escherichia coli: mutant hosts that allow synthesis of some membrane proteins and globular proteins at high levels. J. Mol. Biol. 260 (1996) 289-298.

[5] H.P. Sorensen, K.K. Mortensen, Soluble expression of recombinant proteins in the cytoplasm of Escherichia coli. Microb. Cell. Fact. 4 (2005) 1. 
[6] G.B. Melikyan, Common principles and intermediates of viral protein-mediated fusion: the HIV-1 paradigm. Retrovirology 5 (2008) 111.

[7] M.L. Linial, Foamy viruses are unconventional retroviruses. J. Virol 73 (1999) 17471755.

[8] A. Rethwilm, Unexpected replication pathways of foamy viruses. J. Acquir. Immune Defic. Syndr. Hum. Retrovirol. 13 Suppl 1 (1996) S248-253.

[9] O. Erlwein, M.O. McClure, Progress and prospects: Foamy virus vectors enter a new age. Gene Ther. (2010).

[10] G.D. Trobridge, Foamy virus vectors for gene transfer. Expert Opin. Biol. Ther. 9 (2009) 1427-1436.

[11] T. Wiktorowicz, K. Peters, N. Armbruster, A.F. Steinert, A. Rethwilm, Generation of an improved foamy virus vector by dissection of cis-acting sequences. J. Gen. Virol. 90 (2009) 481-487.

[12] V. Geiselhart, A. Schwantes, P. Bastone, M. Frech, M. Lochelt, Features of the Env leader protein and the $\mathrm{N}$-terminal Gag domain of feline foamy virus important for virus morphogenesis. Virology 310 (2003) 235-244.

[13] D. Lindemann, P.A. Goepfert, The foamy virus envelope glycoproteins. Curr. Top. Microbiol. Immunol. 277 (2003) 111-129.

[14] G. Wang, M.J. Mulligan, Comparative sequence analysis and predictions for the envelope glycoproteins of foamy viruses. J. Gen. Virol. 80 ( Pt 1) (1999) 245-254.

[15] D. Luftenegger, M. Picard-Maureau, N. Stanke, A. Rethwilm, D. Lindemann, Analysis and function of prototype foamy virus envelope $\mathrm{N}$ glycosylation. J. Virol 79 (2005) 7664-7672.

[16] T. Wilk, F. de Haas, A. Wagner, T. Rutten, S. Fuller, R.M. Flugel, M. Lochelt, The intact retroviral Env glycoprotein of human foamy virus is a trimer. J. Virol 74 (2000) 2885-2887.

[17] M. Muhle, A. Bleiholder, S. Kolb, J. Hubner, M. Lochelt, J. Denner, Immunological properties of the transmembrane envelope protein of the feline foamy virus and its use for serological screening. Virology 412 (2011) 333-340.

[18] A. Bleiholder, M. Muhle, T. Hechler, S. Bevins, S. Vandewoude, J. Denner, M. Lochelt, Pattern of seroreactivity against feline foamy virus proteins in domestic cats from Germany. Vet. Immunol. Immunopathol. 143 (2011) 292-300.

[19] M. Lochelt, H. Zentgraf, R.M. Flugel, Construction of an infectious DNA clone of the full-length human spumaretrovirus genome and mutagenesis of the bel 1 gene. Virology 184 (1991) 43-54.

[20] K.L. Guan, J.E. Dixon, Eukaryotic proteins expressed in Escherichia coli: an improved thrombin cleavage and purification procedure of fusion proteins with glutathione S-transferase. Anal. Biochem. 192 (1991) 262-267.

[21] N. Sreerama, R.W. Woody, Computation and analysis of protein circular dichroism spectra. Methods Enzymol.383 (2004) 318-351.

[22] N. Sreerama, R.W. Woody, Estimation of protein secondary structure from circular dichroism spectra: comparison of CONTIN, SELCON, and CDSSTR methods with an expanded reference set. Anal. Biochem. 287 (2000) 252-260.

[23] W.C. Johnson, Analyzing protein circular dichroism spectra for accurate secondary structures. Proteins 35 (1999) 307-312. 
[24] N. Sreerama, R.W. Woody, On the analysis of membrane protein circular dichroism spectra. Protein Sci. 13 (2004) 100-112.

[25] B. Rost, G. Yachdav, J. Liu, The PredictProtein server. Nucleic Acids Res. 32 (2004) W321-326.

[26] A. Frey, J. Di Canzio, D. Zurakowski, A statistically defined endpoint titer determination method for immunoassays. J. Immunol. Methods 221 (1998) 35-41.

[27] R. Levy, R. Weiss, G. Chen, B.L. Iverson, G. Georgiou, Production of correctly folded Fab antibody fragment in the cytoplasm of Escherichia coli trxB gor mutants via the coexpression of molecular chaperones. Protein Expr. Purif. 23 (2001) 338-347.

[28] K. Maskos, M. Huber-Wunderlich, R. Glockshuber, DsbA and DsbC-catalyzed oxidative folding of proteins with complex disulfide bridge patterns in vitro and in vivo. J. Mol. Biol. 325 (2003) 495-513.

[29] L. Dumon-Seignovert, G. Cariot, L. Vuillard, The toxicity of recombinant proteins in Escherichia coli: a comparison of overexpression in BL21(DE3), C41(DE3), and C43(DE3). Protein Expr. Purif. 37 (2004) 203-206.

[30] Rosetta ${ }^{\mathrm{TM}}$ 2(DE3) Competent Cells for enhanced coverage of codon bias in E. coli, inNovations, 2003, pp. 28-29.

[31] A. Sivashanmugam, V. Murray, C. Cui, Y. Zhang, J. Wang, Q. Li, Practical protocols for production of very high yields of recombinant proteins using Escherichia coli. Protein Sci. 18 (2009) 936-948.

[32] C.H. Schein, Optimizing protein folding to the native state in bacteria. Curr. Opin. Biotechnol. 2 (1991) 746-750.

[33] E. McNally, R. Sohn, S. Frankel, L. Leinwand, Expression of myosin and actin in Escherichia coli. Methods Enzymol. 196 (1991) 368-389.

[34] F. Baneyx, Recombinant protein expression in Escherichia coli. Curr. Opin. Biotechnol. 10 (1999) 411-421.

[35] G. Holzwarth, P. Doty, The Ultraviolet Circular Dichroism of Polypeptides. J. Am. Chem. Soc. 87 (1965) 218-228.

[36] M. Hammarstrom, N. Hellgren, S. van Den Berg, H. Berglund, T. Hard, Rapid screening for improved solubility of small human proteins produced as fusion proteins in Escherichia coli. Protein Sci.11 (2002) 313-321.

[37] W. Peti, R. Page, Strategies to maximize heterologous protein expression in Escherichia coli with minimal cost. Protein Expr. Purif. 51 (2007) 1-10.

[38] R. Vincentelli, S. Canaan, J. Offant, C. Cambillau, C. Bignon, Automated expression and solubility screening of His-tagged proteins in 96-well format. Anal. Biochem. 346 (2005) 77-84.

[39] R.K. Knaust, P. Nordlund, Screening for soluble expression of recombinant proteins in a 96-well format. Anal. Biochem. 297 (2001) 79-85.

[40] Y.P. Shih, W.M. Kung, J.C. Chen, C.H. Yeh, A.H. Wang, T.F. Wang, Highthroughput screening of soluble recombinant proteins. Protein Sci. 11 (2002) 1714-1719.

[41] U. Fiebig, O. Stephan, R. Kurth, J. Denner, Neutralizing antibodies against conserved domains of $\mathrm{p} 15 \mathrm{E}$ of porcine endogenous retroviruses: basis for a vaccine for xenotransplantation? Virology 307 (2003) 406-413.

[42] S. Langhammer, U. Fiebig, R. Kurth, J. Denner, Neutralising antibodies against the transmembrane protein of feline leukaemia virus (FeLV). Vaccine 23 (2005) 3341-3348. 
[43] U. Fiebig, M.G. Hartmann, N. Bannert, R. Kurth, J. Denner, Transspecies transmission of the endogenous koala retrovirus. J. Virol 80 (2006) 5651-5654.

[44] O. Garkavenko, M.C. Croxson, M. Irgang, A. Karlas, J. Denner, R.B. Elliott, Monitoring for presence of potentially xenotic viruses in recipients of pig islet xenotransplantation. J. Clin. Microbiol. 42 (2004) 5353-5356.

[45] V. Specke, R. Plesker, J. Wood, C. Coulibaly, K. Suling, C. Patience, R. Kurth, H.J. Schuurman, J. Denner, No in vivo infection of triple immunosuppressed non-human primates after inoculation with high titers of porcine endogenous retroviruses. Xenotransplantation 16 (2009) 34-44.

[46] R. Behrendt, U. Fiebig, R. Kurth, J. Denner, Induction of Antibodies Binding to the Membrane Proximal External Region of gp36 of HIV-2. Intervirology (2011).

[47] S. Frankel, R. Sohn, L. Leinwand, The use of sarkosyl in generating soluble protein after bacterial expression. Proc. Natl. Acad. Sci. U S A 88 (1991) 1192-1196.

[48] J. Denner, Towards an AIDS vaccine: The transmembrane envelope protein as target for broadly neutralizing antibodies. Hum. Vaccin. 7 (2011). 


\section{Figure Legends}

Fig. 1. Schematic presentation of expression constructs. (A) Parental expression vector pGEX-KG and the applied cloning strategy. pGEX-KG was digested with SmaI/XhoI and PCR amplicons coding for the ectodomain of the TM proteins of FFV (in this case codonoptimized) or PFV were ligated into the linearised vector. In addition, an N-terminal Factor-Xa cleavage site and a C-terminal His-Tag (not shown) were introduced. (B) Structural features of the FV envelope proteins and presentation of resulting recombinant proteins. ELP - envelope leader peptide, SU - surface envelope protein, FP - fusion peptide, TM - transmembrane envelope protein, MSD - membrane spanning domain. The black arrows indicate furin cleavage sites. Amino acid numbering is corresponding to Uniprot entry $\underline{\mathbf{0 5 6 8 6 1}}$ for FFV and $\underline{\mathbf{Q 8 7 0 4 1}}$ for PFV, respectively. The theoretical molecular weights are indicated on the right.

Fig. 2. Strategy to optimise protein expression in 96 deep well plates. Four bacterial strains (strain 1-4), three growth media (M1, M2, M3), three IPTG concentrations (grey arrows) and two transformants (clone 1, clone 2) along with the empty vector as control were used. One plate was used for every temperature to be investigated. This design allowed easy transfer to subsequent SDS PAGE analysis by multichannel pipettes.

Fig. 3. Influence of the expression conditions on protein production. Bacterial strains SHuffle T7, C43, SCS-1, and Rosetta 2 were transformed with the expression constructs of the TM proteins of FFV and PFV and two transformants (TM1, TM2) along with the 
empty expression vector $(\mathrm{KG})$ were grown in different media (LB, 2YT, TB). Expression was induced with increasing concentrations of IPTG (grey arrows, corresponding to 0 , 0.1 and $1 \mathrm{mM}$ IPTG). Recombinant proteins and GST from the parental vector are indicated by black arrows.

Fig. 4. Gelfiltration of the affinity purified TM protein of FFV (A) and that of PFV (B). Separations were performed on a Superdex 200 10/300 GL column with PBS, $0.1 \%$ sarkosyl at $0.4 \mathrm{ml} / \mathrm{min}$. Inset: Analysis of elution fractions 1-7 by SDS PAGE along with a sample of material loaded on the column (IN). Numbers on the right indicate molecular weights, Vo-dead volume of the column.

Fig. 5. Expression of the TM protein of FFV (A) and that of PFV (B) under nonoptimised and optimised conditions and their purification. Lane M, molecular weight marker; L, non-induced lysate; IL, induced lysate; E, elution fraction of the GST fusion protein after gel filtration, $\mathrm{E}_{\mathrm{T}}$, elution fraction of the $\mathrm{TM}$ protein after thrombin digestion.

Fig. 6. Analytical gel filtration of the thrombin treated TM protein of FFV (A) and that of PFV (B). Proteins were analysed on a Superdex 75 column in PBS, $0.1 \%$ sarkosyl at a flow rate of $0.4 \mathrm{ml} / \mathrm{min}$ (black solid lines). Ovalbumin with a molecular weight of $43 \mathrm{kDa}$ was run under identical conditions as molecular weight marker (grey dashed line). 
Fig. 7. Circular dichroism analysis of the purified GST TM fusion protein (grey dashed line) and the TM protein (black solid line) of FFV (A) and PFV (B). The were analysed in a Jasco 720 spectropolarimeter at wavelengths of $260-195 \mathrm{~nm}$.

Fig. 8. Comparative ELISA of proteins purified by an urea/on column refolding (black bars) or the sarkosyl extraction method (grey bars). The GST TM fusion protein of FFV purified by both protocols were coated on ELISA plates and incubated with cat sera of known serological FFV infection status.

Fig. S1. Expression levels and solubility of the TM proteins of FFV (A) and PFV (B) produced under non-optimised conditions in BL21 cells, L, lysate without inducer, IL+, induced lysate, SN, supernatant; P pellet. In the Western blot (WB) analysis antibodies against the His tag were used. The TM protein is marked by an arrow.

Fig. S2. Expression levels and solubility of the TM proteins of FFV (A) and PFV (B) produced under different conditions in different bacteria, L, lysate without inducer, IL, induced lysate, SN, supernatant; P pellet. In the Western blot (WB) analysis antibodies against the His tag were used. The TM protein is marked by an arrow.

Fig. S3. Solubilisation of the TM protein of FFV using various detergents. (A) Producing cells were lysed with PBS, lysozyme and cell debris were removed by low speed centrifugation (TL, total lysate). The supernatants were split in one millilitre fractions and centrifuged for one hour at $16.000 \mathrm{~g}$ (SN, supernatant; IP, insoluble pellet (IP). The other 
pellets were extracted with 1 or $10 \%$ of the indicated detergents (SY, sarkosyl, NP, NP40, TX, Triton-X 100, TW, Tween 20, OG, OG-beta, DM, dodecylmaltoside, CH, CHAPS, B35, Brij35, Mix, sarkosyl, CHAPS, Triton-X 100) for three hours at room temperature and centrifuged at high speed for thirty minutes and the supernatants were loaded. The TM protein of FFV is indicated by an arrow; in the Western blot analysis an antiserum against GST was used.

Fig. S4. Influence of sarkosyl on solubility (A) and enzymatic activity (B) of the GST TM fusion protein of PFV. (A) Pellets from TM protein producer cells were incubated with PBS containing lysozyme $(0.1 \mathrm{mg} / \mathrm{ml})$ on ice for 15 minutes, $5 \mathrm{mM}$ DTT and the indicated amount of sarkosyl were added, after sonification for $3 \times 10 \mathrm{~s}$ and 10 minutes rotation at room temperature the total lysates (TL) were centrifuged for 10 minutes at $10.000 \mathrm{~g}$ to separate supernatants (SN) and pellet (P). GST TM fusion protein of PFV is marked by an arrow. (B) Kinetics of the GST activity of each sample shown in (A), purified GST $(0.176 \mathrm{ug} / \mathrm{ml})$ was used as control. The red line marks 10 min incubation (C) GST activity at 10 minutes as shown in (B). The red circle marks the concentration used for purification under non-denaturing conditions. 
Table 1 Comparison of purity and yields using two different purification protocols (AC = affinity chromatography).

\begin{tabular}{|c|c|c|c|c|c|c|}
\hline & \multicolumn{2}{|c|}{ Urea protocol } & \multicolumn{4}{|c|}{ Sarkosyl protocol } \\
\hline & \multicolumn{2}{|c|}{ FFV TM } & \multicolumn{2}{|c|}{ FFV TM } & \multicolumn{2}{|c|}{ PFV TM } \\
\hline & Purity & Yield & Purity & Yield & Purity & Yield \\
\hline AC and on-column refolding & $95 \%$ & $0.5-0.8 \mathrm{mg} / \mathrm{l}$ & - & - & - & - \\
\hline Rapid dilution refolding and $\mathrm{AC}$ & - & - & $90 \%$ & $14-16 \mathrm{mg} / \mathrm{l}$ & $90 \%$ & $15-18 \mathrm{mg} / \mathrm{l}$ \\
\hline Gel filtration & - & - & $95 \%$ & $12-14 \mathrm{mg} / \mathrm{l}$ & $95 \%$ & $13-16 \mathrm{mg} / \mathrm{l}$ \\
\hline
\end{tabular}


Table 2. Comparison of predicted and measured secondary structure contents in purified foamy virus proteins.

\begin{tabular}{|c|c|c|c|c|c|c|}
\hline & \multicolumn{3}{|c|}{ Predictions } & \multicolumn{3}{|c|}{ CD-Measurements } \\
\hline & $\alpha$-helical & $\beta$-sheets & coiled & $\alpha$-helical & $\beta$-sheets & coiled \\
\hline FFV GST TM & 43.6 & 15.2 & 41.2 & 37.5 & 15.1 & 47.5 \\
\hline FFV TM & 39.2 & 22.2 & 38.7 & 41.1 & 12.2 & 46.6 \\
\hline PFV GST TM & 45.8 & 14.2 & 39.9 & 37.9 & 16.0 & 46.3 \\
\hline PFV TM & 41.8 & 20.7 & 37.5 & 37.0 & 15.9 & 47.2 \\
\hline
\end{tabular}




\section{Muehle et al., Figure 1}

A

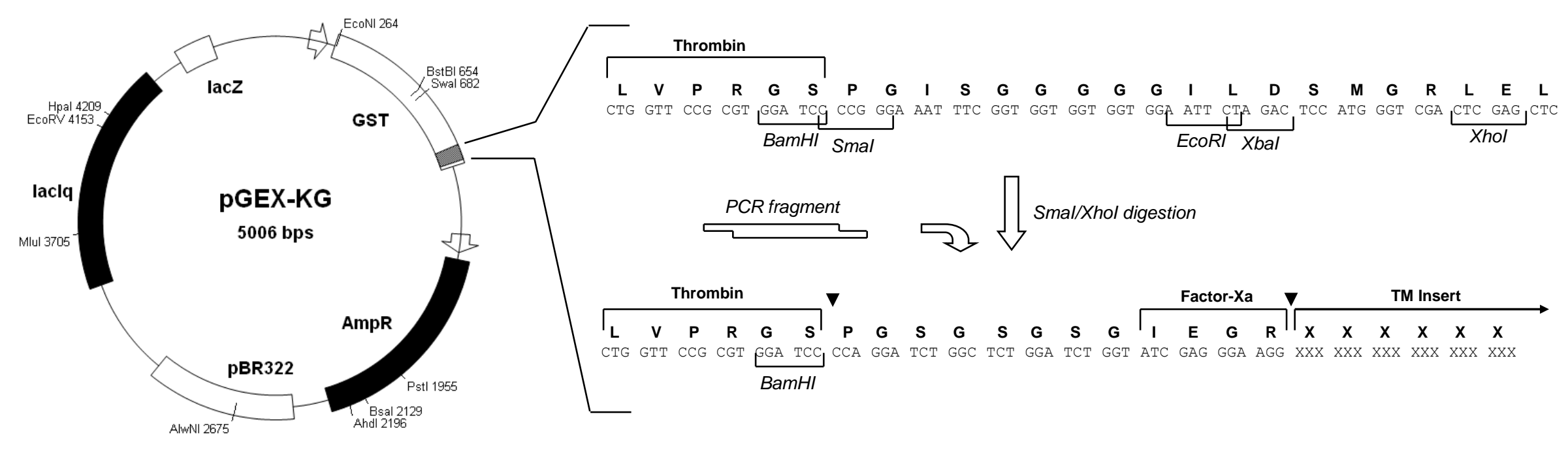

B

\begin{tabular}{|c|c|c|c|c|c|c|}
\hline FV Env & ELP & SU & FP & TM & MSD & \\
\hline & & \multicolumn{3}{|c|}{ ectodomain } & \\
\hline FFV-TM & & GST- & & & -His & $68.2 \mathrm{kDa}$ \\
\hline & & 600 & & & 961 & \\
\hline PFV-TM & & GST- & & & -His & $69.0 \mathrm{kDa}$ \\
\hline
\end{tabular}


Muehle et al., Figure 2

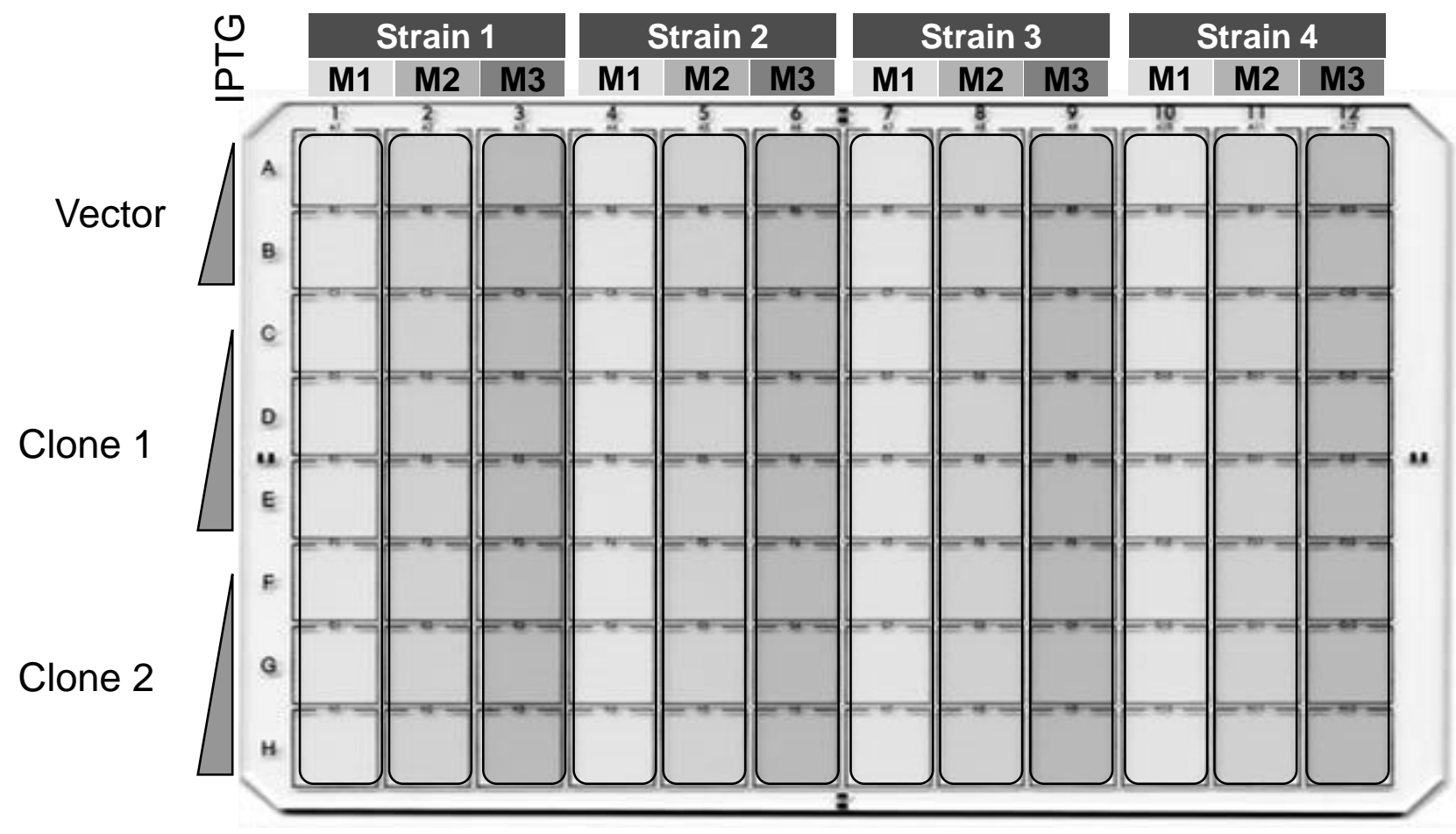




\section{Muehle et al., Figure 3}

A

Shuffle T7

C43

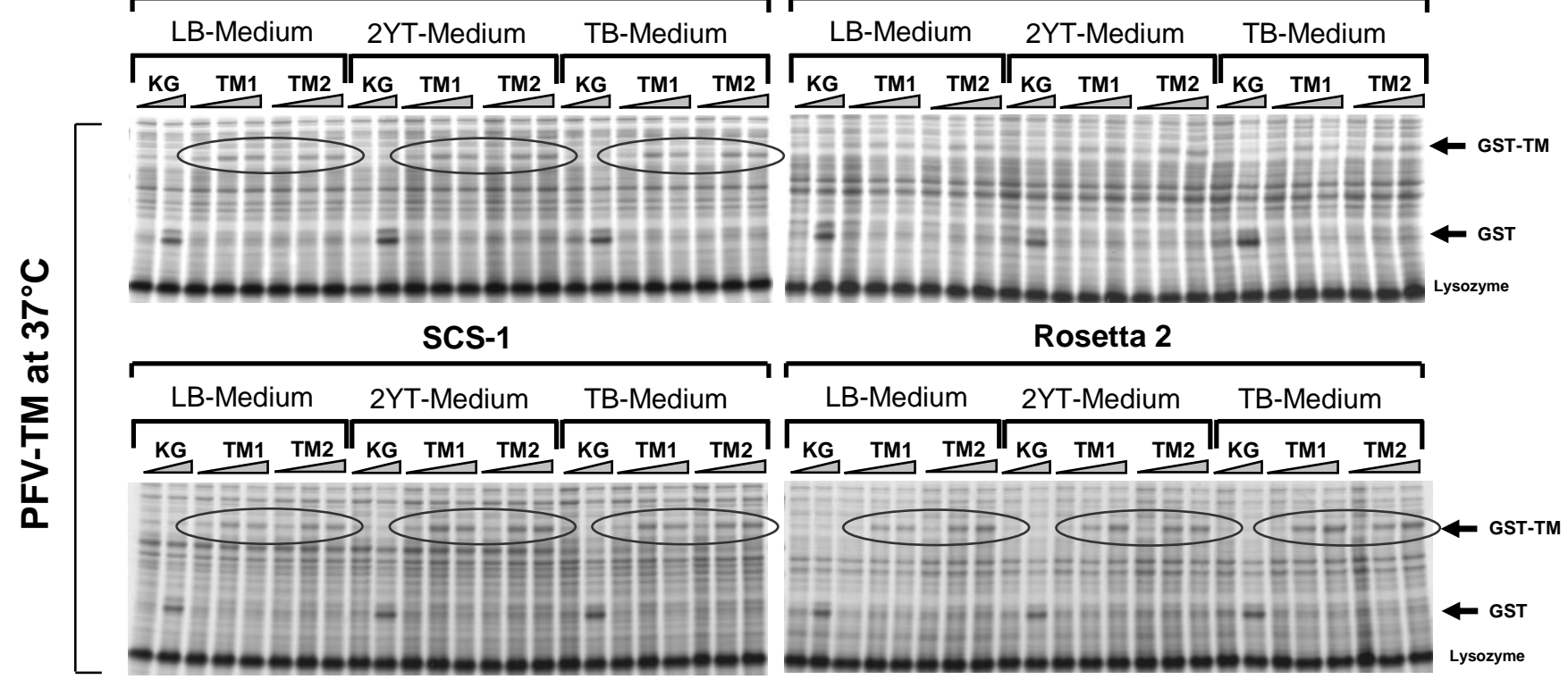

B

Shuffle T7

C43

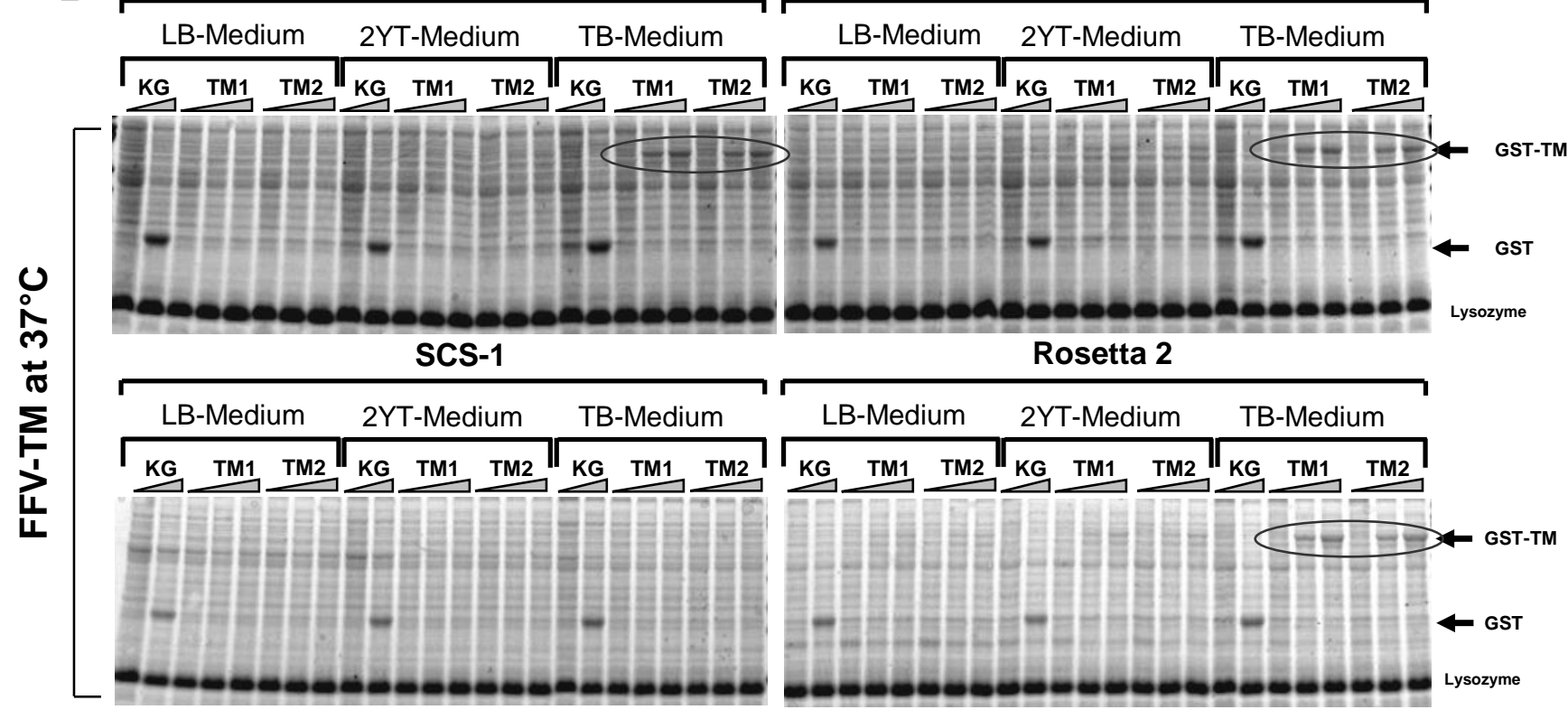




\section{Muehle et al., Figure 4}
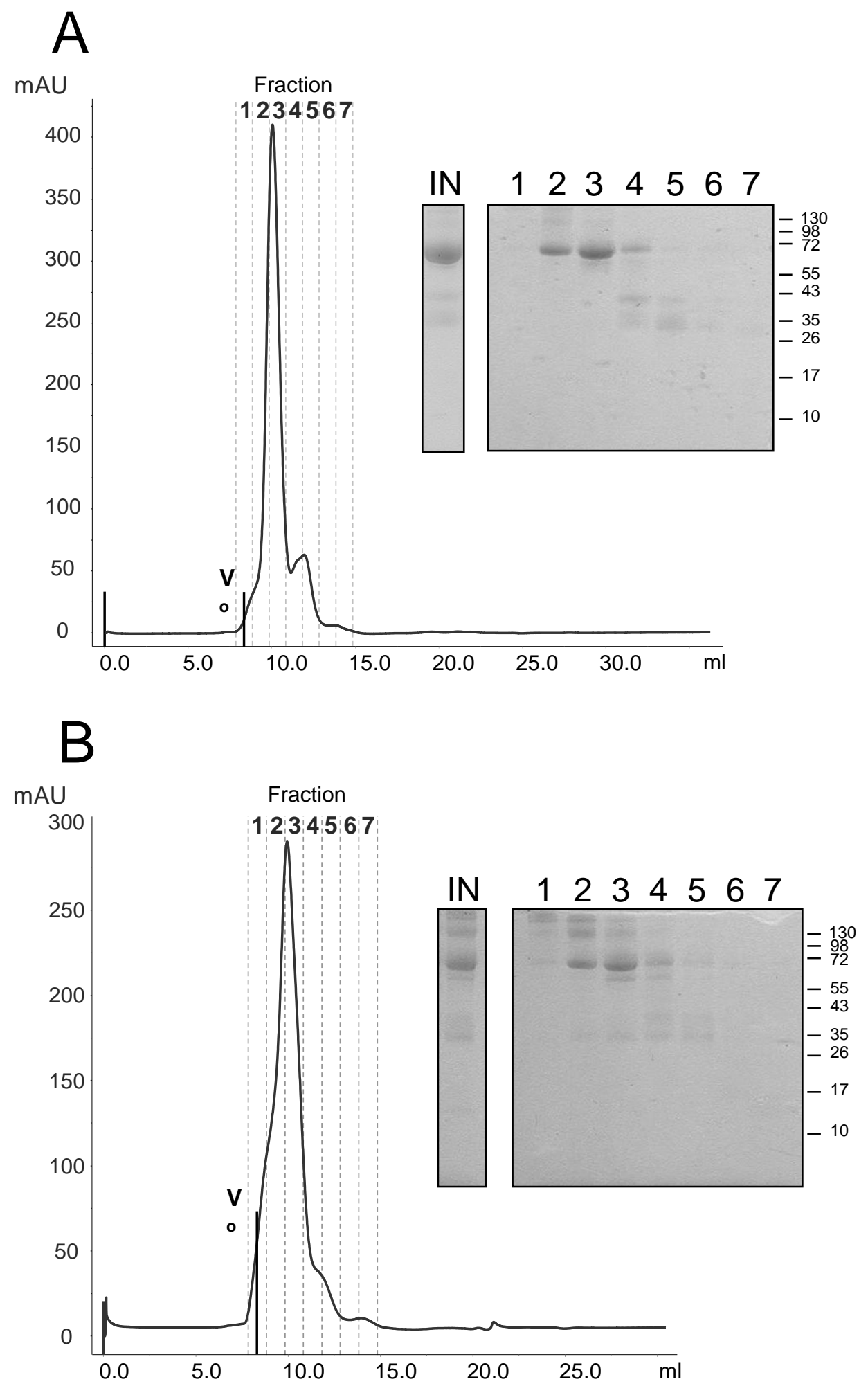


\section{Muehle et al., Figure 5}

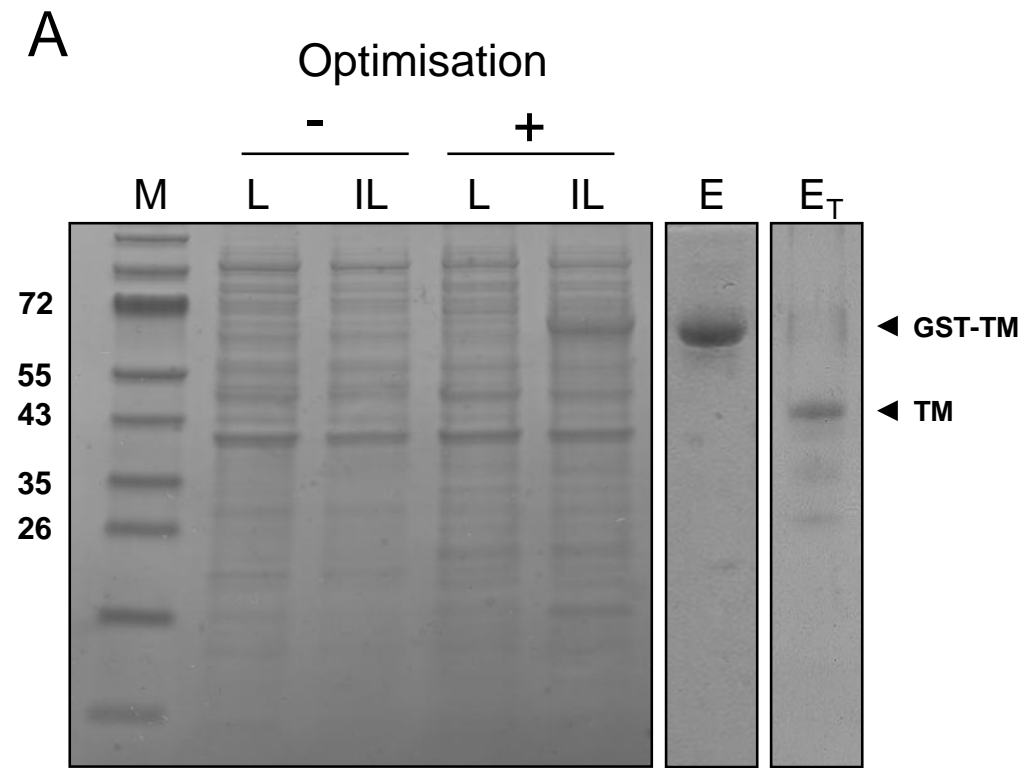

FFV TM
B Optimisation

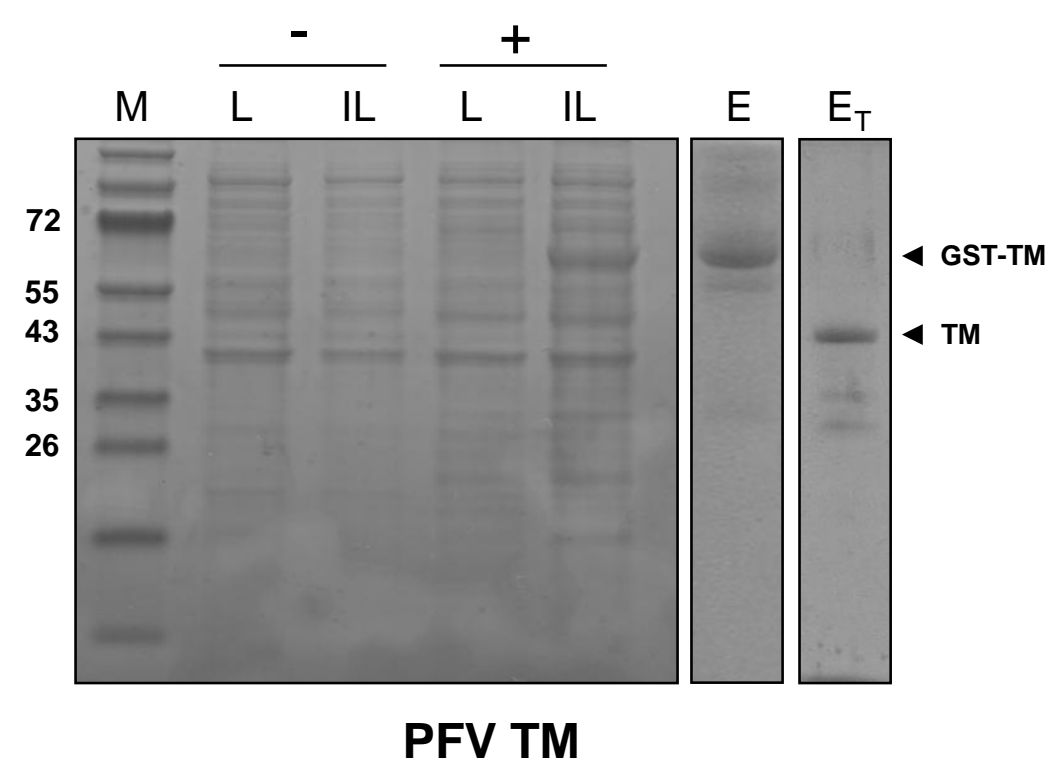


Muehle et al., Figure 6

A

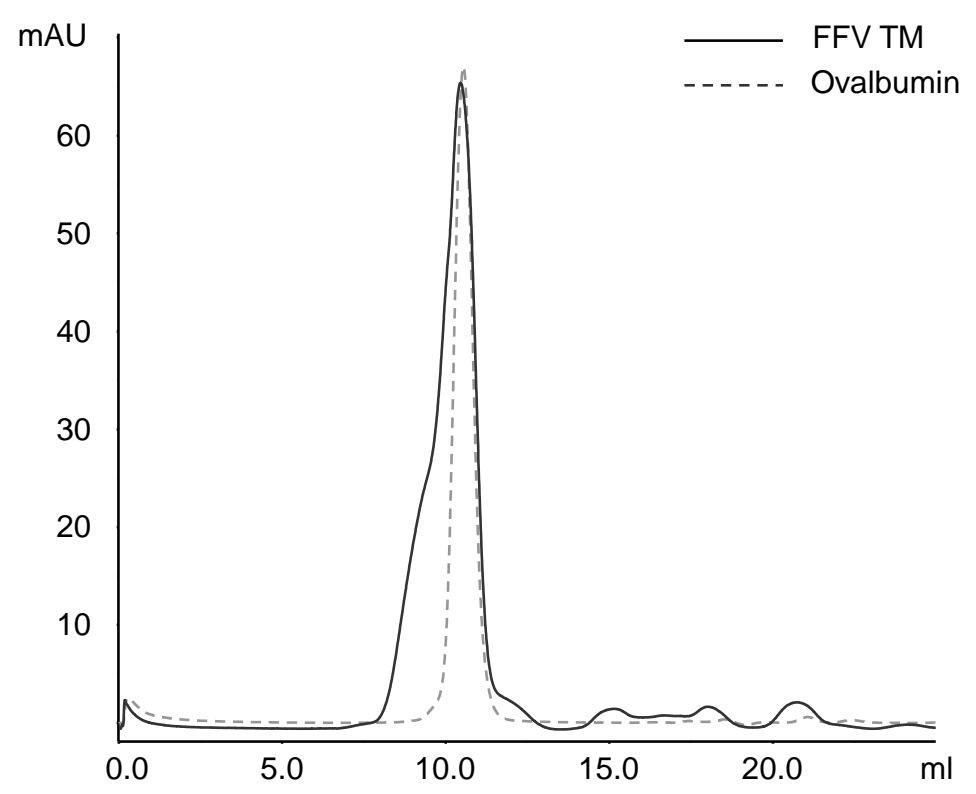

B

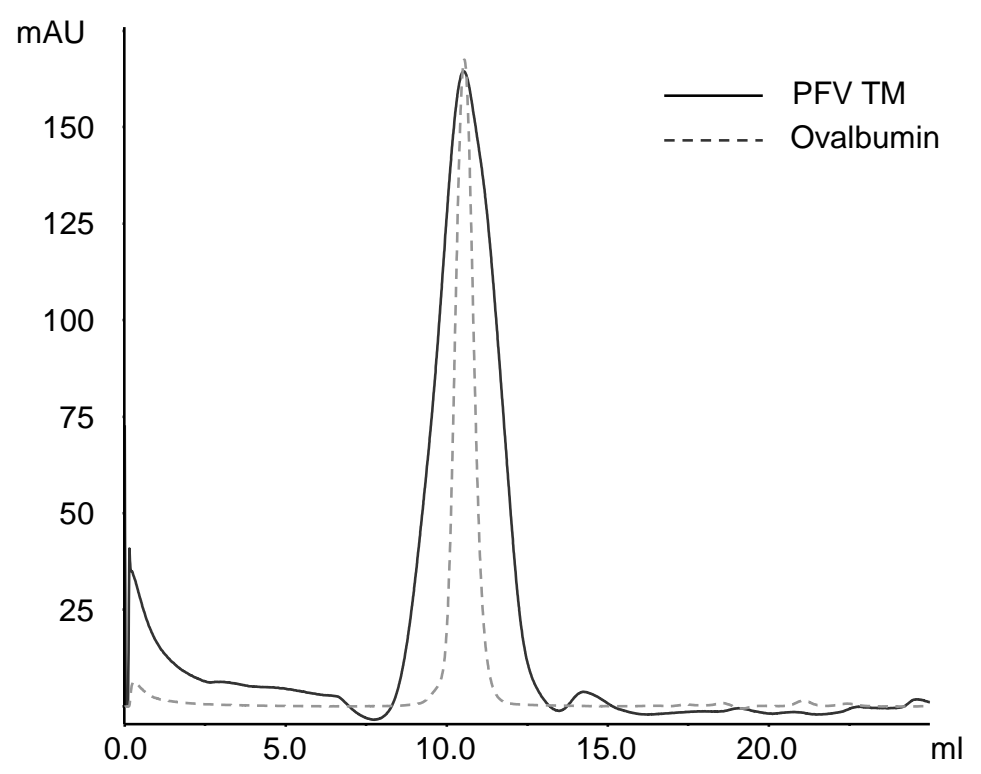




\section{Muehle et al., Figure 7}

A
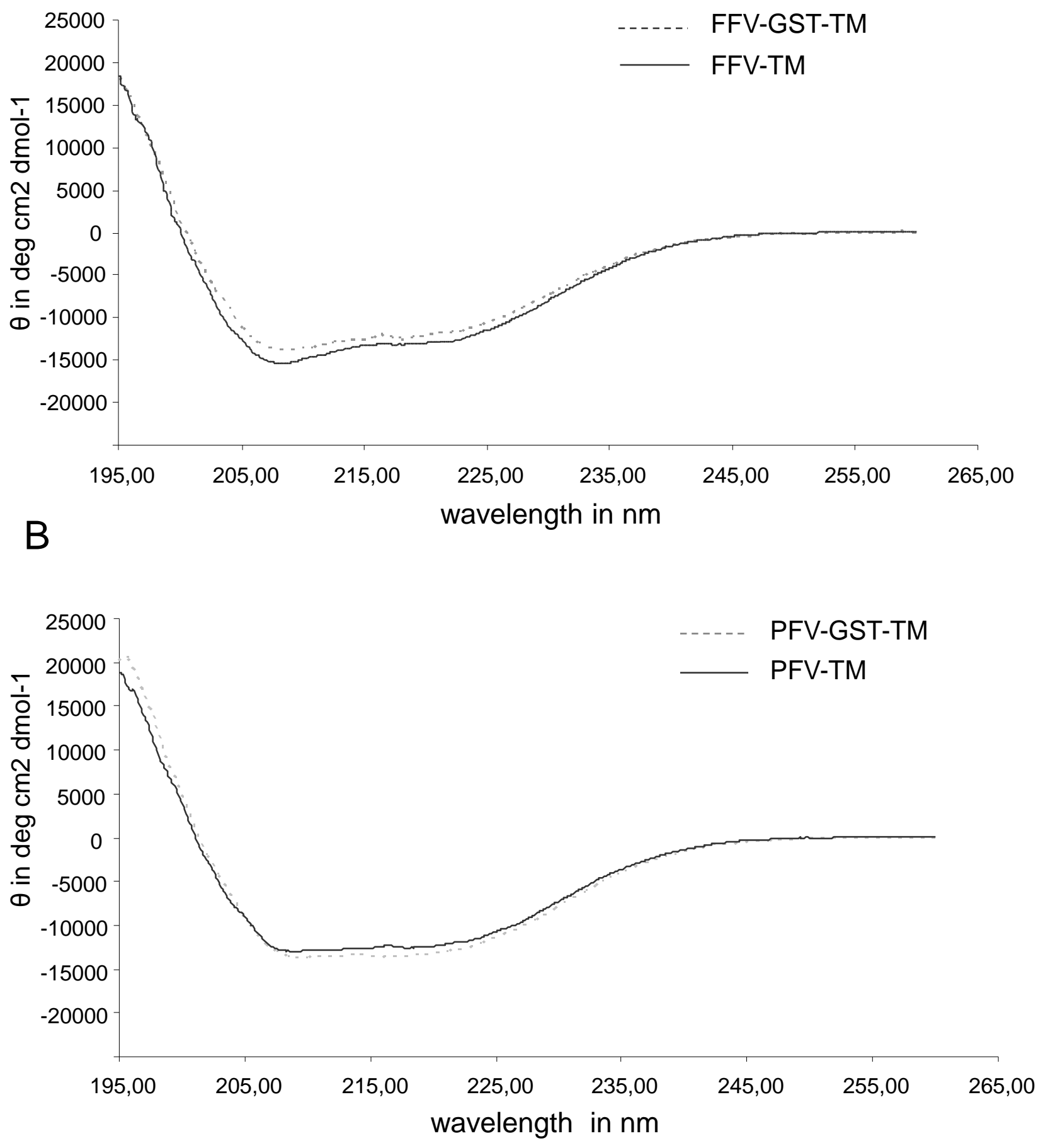


\section{Muehle et al., Figure 8}

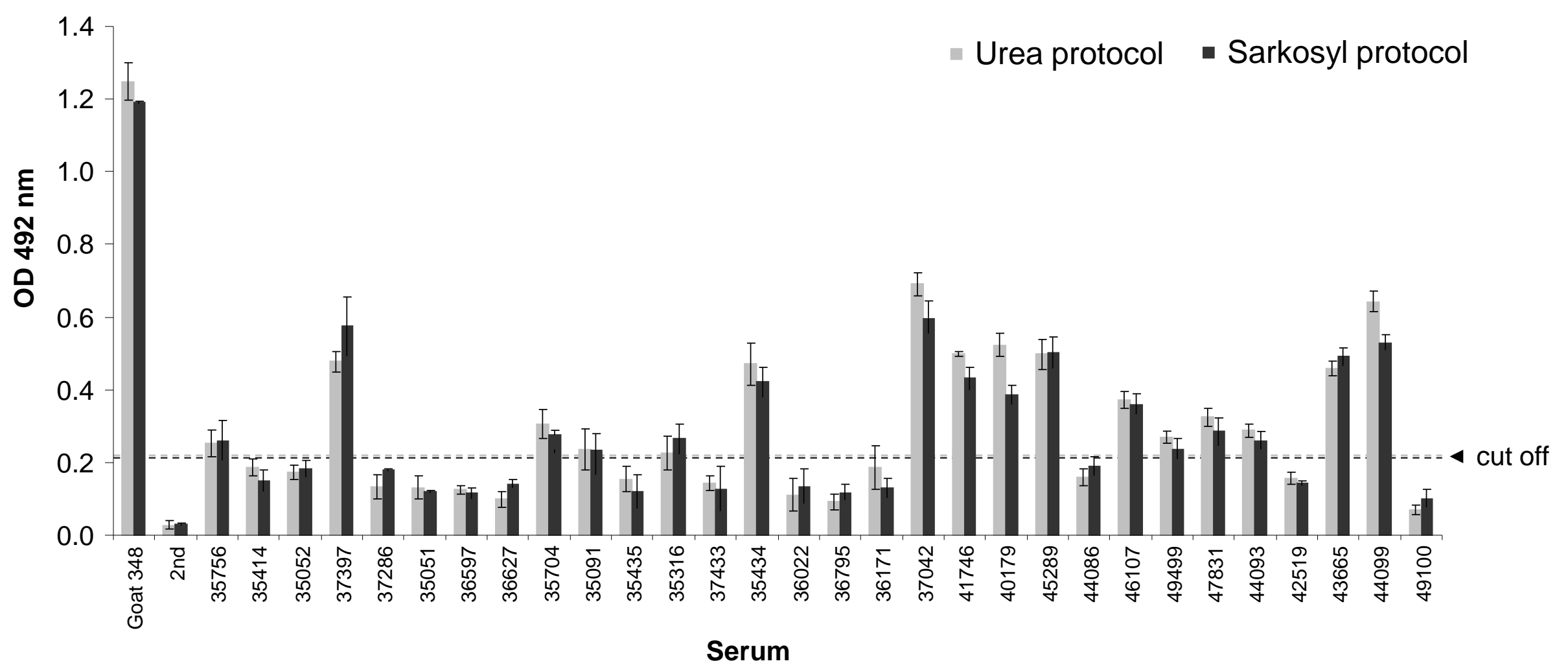




\section{Highlights}

- Expression and purification of the transmembrane envelope proteins of foamy viruses

- $\quad$ Screening assay for optimisation of expression in 96 deep well plates

- Characterisation of purified proteins by gel filtration and circular dichroism

- Application in immunological assays screening for foamy virus infection 